\title{
Modulation of Alpha 1 Adrenergic Receptors on Urinary Bladder in Rat Spinal Cord Injury Model
}

\author{
Gilho Lee, Heeyoon Park, Hong Suk Park ${ }^{1}$ Jeong Gu Lee ${ }^{1}$ \\ Department of Urology, Dankook University College of Medicine, Cheonan; ${ }^{1}$ Department of Urology, Korea University College of Medicine, Seoul, Korea
}

\begin{abstract}
Purpose: Whereas many studies have focused on the vesical changes of the $\alpha 1$ adrenergic receptor (AR) subtypes in partial outlet obstruction, few studies have addressed the modulation of the al AR subtypes after spinal cord injury (SCI). Therefore, we studied the modulation of the al ARs in urinary bladder in a rat SCI model.

Methods: Four weeks after a SCI, the whole vesical bodies from eight female Sprague-Dawley rats and from eight controls were harvested. The total RNA was extracted from the samples and was used to prepare cDNA. We developed standard plasmid constructs of glyceraldehyde-3-phosphate dehydrogenase (GAPDH) and three al ARs ( $\alpha 1 \mathrm{a}, \alpha 1 \mathrm{~b}$, and $\alpha 1 \mathrm{ld})$ to convert the cycle threshold $(\mathrm{Ct})$ values from real-time polymerase chain reaction (RT-PCR) into subtype mRNA concentrations. The detected Ct values of 16 samples from RT-PCR were interpolated into the standard plasmid curves.

Results: All serially diluted standard samples showed very good linearity. The mRNA expression of GAPDH was higher in the SCI group, whereas the mRNA expression of all $\alpha 1$ ARs was lower in the SCI group than in the control animals. The $\alpha 1 \mathrm{a}, \alpha 1 \mathrm{~b}$, and ald mRNA expression in the controls was $81.7 \%, 3.3 \%$, and $15.1 \%$, respectively, whereas the $\alpha 1 \mathrm{a}$, $\alpha 1 \mathrm{~b}$, and ald mRNA expression in the SCI group was $33.5 \%, 5.2 \%$, and $60.9 \%$, respectively.

Conclusions: SCI moderates the a1 AR mRNA subtypes in the urinary bladder. The relatively increased ald or decreased ala AR mRNA expression may be a therapeutic candidate for controlling the symptoms of neurogenic bladder after SCI.
\end{abstract}

Keywords: Spinal cord injuries; Urinary bladder; Alpha adrenergic receptors

\section{INTRODUCTION}

The prevalence of spinal cord injury (SCI) in young patients is increasing, thus leading to an increased need for lifelong care of these patients [1]. For this reason, it is increasingly important to understand the complications in the urinary bladder of SCI individuals who complain of voiding symptoms or impaired bladder emptying.

Detrusor-sphincter-dyssynergia (DSD), a condition characterized by simultaneous contraction of the detrusor and urethral sphincter, is one of the causes of inefficient bladder emptying after SCI [2].

Traditionally, ala adrenergic receptor (AR) antagonists have been used to decrease the maximum urethral closing pressure and the symptoms of DSD after SCI [2,3]; however, recent studies have shown that the roles of the ala ARs extend beyond the urethra or the urinary bladder neck. Because all ala AR subtypes are expressed in the bladder body, it is reasonable to assume that selective al AR antagonists may have on specific roles not only in the bladder neck but also in the bladder body [4-7]. However, the molecular characterization of the AR subtypes in the body of the urinary bladder is not well established.

Three $\alpha 1$ ARs ( $\alpha 1 \mathrm{a}, \alpha 1 \mathrm{~b}$, and $\alpha 1 \mathrm{~d})$ have been cloned with the use of molecular technologies and have been characterized pharmacologically $[8,9]$. Because the ala AR subtype predominates in the smooth muscle of the prostate and the proximal urethra,
Corresponding author: Gilho Lee

Department of Urology, Dankook University College of Medicine,

119 Dandae-ro, Dongnam-gu, Cheonan 330-997, Korea

Tel: +82-41-550-6630 / Fax: +82-41-551-6630 / E-mail: prostate@ymail.com

Submitted: April 3, 2012 / Accepted after revision: May 29, 2012
This is an Open Access article distributed under the terms of the Creative Commons Attribution Non-Commercial License (http://creativecommons.org/licenses/by-nc/3.0/) which permits unrestricted non-commercial use, distribution, and reproduction in any medium, provided the original work is properly cited. 
this subtype has been assumed to be responsible for the dynamic component of obstruction and the related voiding symptoms [8-12]. Interestingly, the relative expression of the al AR subtypes is changed with chronic outlet obstructive lesions in the rat urinary bladder, with a remarkable increase in bladder ald AR expression but a decrease in bladder ala AR expression [7]. These findings imply that the ald AR may be a new therapeutic target for controlling irritable bladder symptoms [12].

The recently developed selective a1d AR antagonist naftopidil and the selective ala AR antagonist silodosin are used for the treatment of lower urinary tract symptoms around the world. Interestingly, the selective ald AR antagonist naftopidil improves not only voiding symptoms but also storage symptoms in patients with benign prostatic hyperplasia [13]. The improvement of storage symptoms such as urgency and frequency may be assumed to be from the vesical modulation of a 1 AR subtypes in chronic urinary obstructive lesions $[7,12,13]$.

It is well known that ineffective bladder emptying in SCI patients causes the accumulation of residual urine and bladder hypertrophy similar to like the plasticity of the urinary bladder in a chronic urinary obstructive model [1,2]. Even though the phenotypes in the urinary bladder are similar between these two types of dysfunction, it is clear that the SCI model and the chronic urinary obstructive model have different causal mechanisms and different pathophysiologic or molecular responses. Furthermore, whereas the genetic modulations of the $\alpha 1 \mathrm{AR}$ subtypes in the urinary bladder are relatively well documented in the chronic obstructive model, there are few reports on the changes of subtypes of al AR subtypes in detrusor muscle after SCI. Furthermore, which of these selective antagonists will be more clinically useful in the treatment of voiding symptoms after SCI is not established. For these reasons, we studied the subtype changes of the al ARs in the urinary bladder in a rat SCI model. Understanding the pharmacologic modulation of the al AR subtypes in the rat model of SCI and the mechanisms underlying this modulation may have implications for the management of neurogenic bladder after SCI.

\section{MATERIALS AND METHODS}

\section{Animals}

All experimental procedures were conducted in accordance with the National Institutes of Health (NIH) guidelines for investigators and those for animal users developed by the NIH animal research advisory committee. A total of 16 Sprague-Dawley fe- male rats, with body weights of $250 \mathrm{~g}$, were used. For SCI, the eighth thoracic cord segment of eight rats was exposed under halothane anesthesia and injury was produced by dropping a $2.0 \mathrm{~mm}$ diameter rod with a weight of $10 \mathrm{~g}$ from a height of 25 $\mathrm{mm}$ onto the exposed spinal cord by use of the New York University Impactor (New York, NY, USA) [14]. Eight controls were subjected to the same operation as the SCI rats but without the contusion injury. Animal care after SCI was performed. The post-injury bladder was manually voided twice daily until voluntary voiding occurred. We assessed the changes in locomotor function after SCI and then maintained the animals for 4 weeks. All animals were terminated at four weeks after SCI. The whole bladders were removed and weighed. The harvested bladder was then stored at $-80^{\circ} \mathrm{C}$. The control rats were sacrificed at the same time as the SCI group.

\section{mRNA Quantification of a1 AR Subtypes: Real-Time Polymerase Chain Reaction (PCR)}

Total RNA was extracted from the whole bladder specimens by using Trizol reagent (Invitrogen, Carlsbad, CA, USA) and chloroform. We designed PCR primers for ala AR, alb AR, ald $A R$, and glyceraldehyde-3-phosphate dehydrogenase (GAPDH), and all primers spanned at least one intron of the corresponding gene (Table 1). We used the ImProm-II Reverse Transcription System (Promega, Madison, WI, USA) to prepare cDNA according to the manufacturer's instructions. To estimate the mRNA expression, calibration curves were made from the measured fluorescence of dilution series of the control plasmids. Then, the concentrations of the unknowns were calculated from standard values. To obtain constructs for plasmid controls (pala AR, palb AR, pald AR, and pGAPDH) for quantifying

Table 1. Primers for reverse transcription polymerase chain reaction

\begin{tabular}{lll}
\hline Primers & Sequences $\left(5^{\prime}{ }^{\prime} \mathbf{3}^{\prime}\right)$ & Reference \\
\hline GAPDH & GTCTTCACCACCACGGAGAAGGC & XR086293.2 \\
& ATGCCAGTGAGCTTCCCGTTCAGC & \\
Alpha 1a & GTAGCCAAGAGAGAAAGCCG & NM017191.2 \\
& CAACCCACCACGATGCCCAG & \\
Alpha 1b & GCTCCTTCTACATCCCGCTCG & NM016991.2 \\
& AGGGGAGCCAACATAAGATGA & \\
Alpha 1d & CGTGTGCTCCTTCTACCTACC & NM024483.1 \\
& GCACAGGACGAAGACACCCAC & \\
\hline
\end{tabular}

GAPDH, glyceraldehyde-3-phosphate dehydrogenase. 
the mRNA of the AR subtypes and GAPDH, partial cDNAs were amplified from a rat urinary bladder sample by using each AR subtype and GAPDH primers (Table 1). These cDNAs were then cloned into the pGEM-T Easy vector (Promega) according to the manufacturer's instructions. Finally, the DNA sequences of the cloned plasmids were checked with the restriction enzyme EcoRI (Fig. 1).

Two microliters of the standard plasmid was added to $25 \mu \mathrm{L}$ of reaction mixture containing each forward primer (300 nM), reverse primer (300 nM), 0.5 unit of uracil-N-glycosylase (Sigma Chemicals, Balcatta, WA, USA), and 2X QuantiTech SYBR Green PCR Master Mix (Qiagen GmbH, Hilden, Germany). Real-time PCR was performed in a Rotor-Gene (Rotor Gene 6.0, Corbett, Sydney, Australia) according to the manufacturer's instructions. Amplification consisted of 2 minutes at $50^{\circ} \mathrm{C}$ for carryover prevention, 15 minutes at $95^{\circ} \mathrm{C}, 10$ seconds denaturation at $95^{\circ} \mathrm{C}$, and annealing at $52^{\circ} \mathrm{C}$ for 15 seconds and $72^{\circ} \mathrm{C}$ for 20 seconds for 40 cycles. Melting curve analysis was performed and concentration values were measured. Negative controls were also included. The detected cycle threshold $(\mathrm{Ct})$ values were interpolated into the standard curves of the plasmid constructs, and the mRNA expression in the samples was calculated [15].

\section{Statistical Analyses}

The changed mRNA concentration in each al AR subtype of

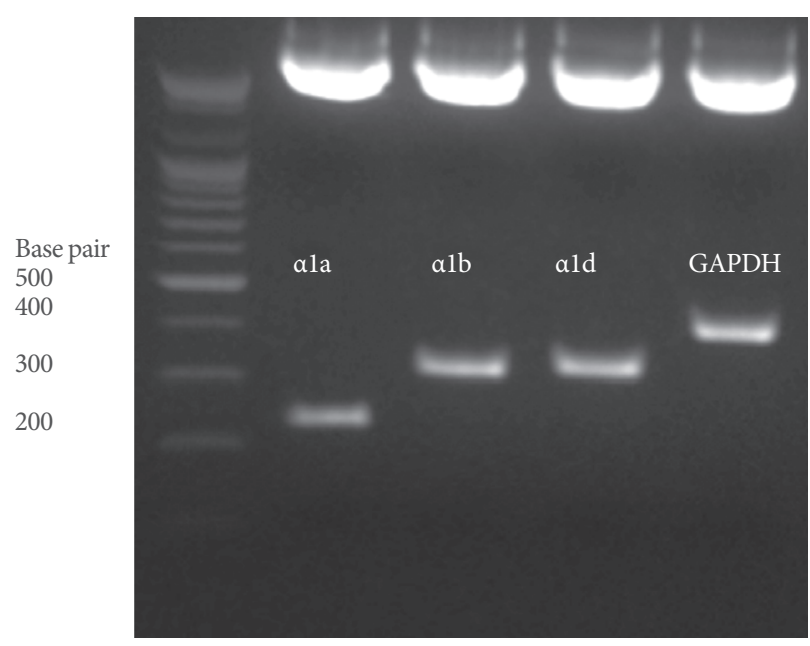

Fig. 1. The cloned control plasmids, pala AR, palb AR, pald $\mathrm{AR}$, and pGAPDH were cut with restriction enzyme (EcoRI). We can see the fragmented or restricted segments, measuring about 200 - to $400 \mathrm{bp}$. GAPDH, glyceraldehyde-3-phosphate dehydrogenase.
SCI rats was compared with the controls by using the MannWhitney test. The statistical difference in the adjusted mRNA expression of the al AR subtypes in the controls and the SCI group was determined by Kruskal-Wallis analysis with post-hoc Mann-Whitney test. P-values $<0.05$ were considered statistically significant.

\section{RESULTS}

All rats showed a typical posture of SCI, the hind limbs were drooped and paralyzed at day 1 after the contusion injury. Significant increase in bladder wet weight was noted in the SCI group (Fig. 2).

\section{Standardization of Real-Time PCR}

The linear relationships of all cloned plasmids from $10^{0}$ to $10^{-5}$ starting copies/reaction revealed high correlations between the copy numbers and the $\mathrm{Ct}$ values. pGAPDH also generated a good log-linear regression plot (Fig. 3).

\section{Changes in mRNA Expression of a1 AR Subtypes}

The SCI group showed statistically increased mRNA expression of GAPDH at 4 weeks after injury compared with the control group (Table 2, Fig. 4A) $(\mathrm{P}=0.041)$. The expression of the $\alpha 1$ AR subtypes was adjusted by the expression of GAPDH in each sample. The adjusted $\alpha 1$ AR subtype expression in the control group was $371.50 \pm 118.19$ for $\alpha 1 \mathrm{a}, 15.11 \pm 7.97$ for $\alpha \mathrm{lb}$, and $68.62 \pm 40.99$ for ald AR. There were significant differences in AR subtype expression in the urinary bladder in controls $(\mathrm{P}=$ 0.001) (Fig. 4B).

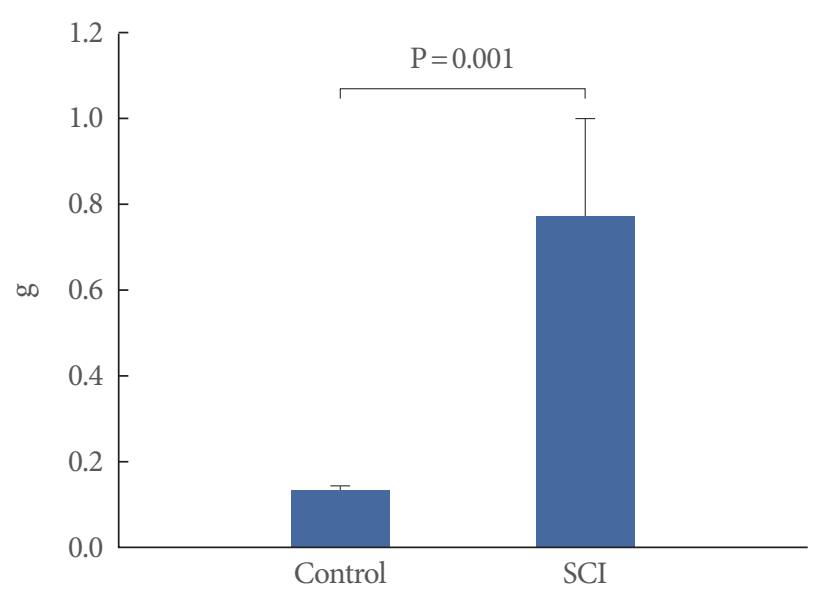

Fig. 2. Weight of urinary bladder in the control and the spinal cord injury (SCI) group. Data are reported as the mean \pm SD. 

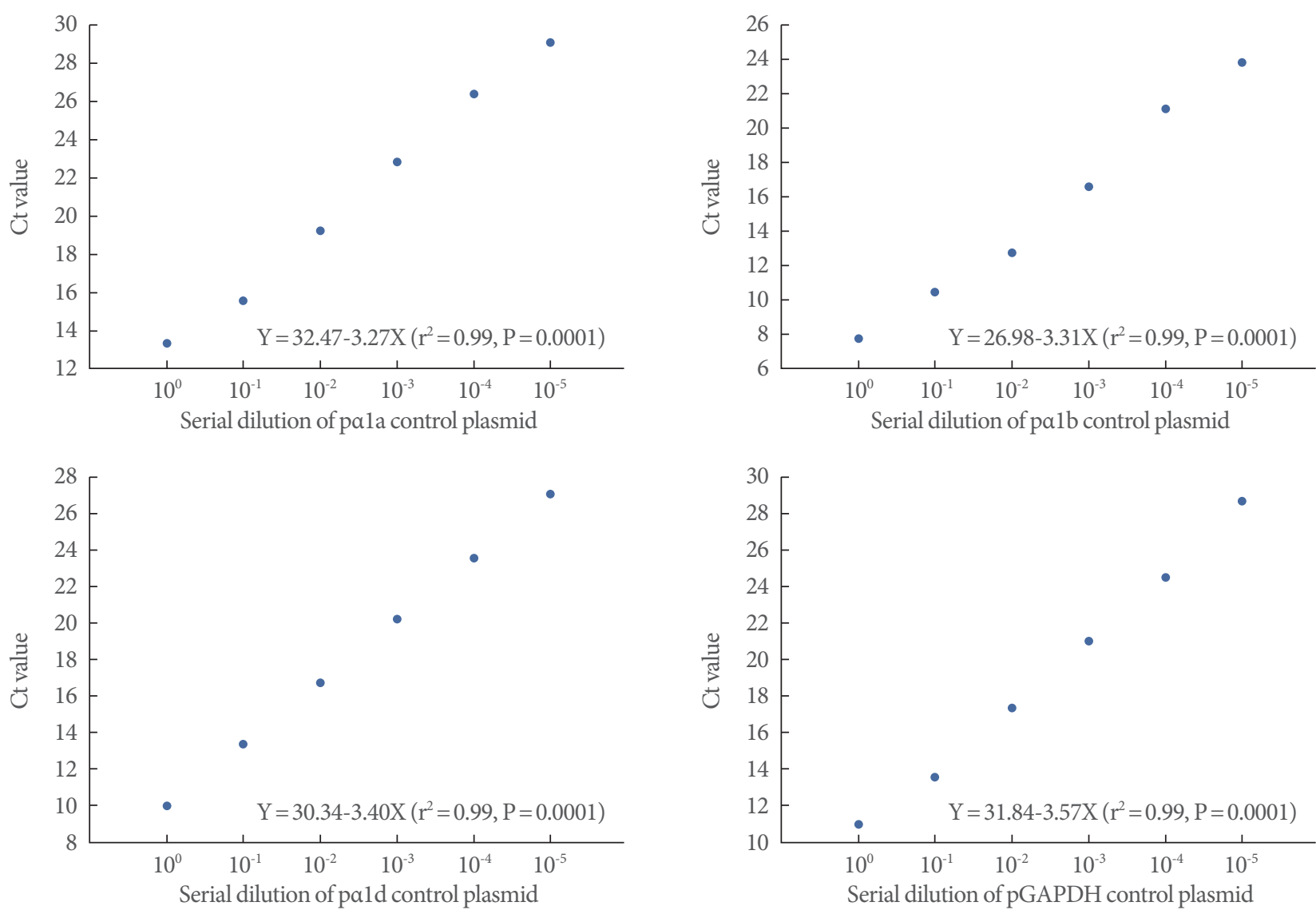

Fig. 3. A linear relationship between the cycle number reaching above threshold of fluorescence and the corresponding log-transformed cDNA values of control plasmids.

The AR subtype expression of the SCI group differed from that of the controls. The adjusted al AR expression in the SCI group was $15.90 \pm 12.13$ for $\alpha 1 \mathrm{a}, 2.48 \pm 2.01$ for $\alpha 1 \mathrm{~b}$, and $28.94 \pm$ 17.61 for ald AR (Fig. 4C). Furthermore, there were significant differences in AR subtype expression in the urinary bladder in the SCI group $(\mathrm{P}=0.001)$. The ald AR was marginally more expressed than the ala AR in the SCI group (P=0.05) (Fig. 4C). The SCI group had statistically less mRNA expression of the $\alpha 1$ ARs than did the control group ( $\alpha 1 \mathrm{a}, \mathrm{P}=0.000$; $\alpha 1 \mathrm{~b}, \mathrm{P}=0.001$; and ald, $\mathrm{P}=0.016$ ) (Fig. 4D).

\section{DISCUSSION}

The communication between the outlet and the bladder body is under the control of the central nervous system as well as the sympathetic, parasympathetic, and somatic nerves that innervate the bladder body muscle and urinary bladder neck $[16,17]$. The interplay between the urinary bladder and the upper con- trol organs can be disrupted as a result of trauma or disease [1$3,16,17]$. In the case of spinal cord transection, voluntary control of voiding is eliminated and is accompanied by an uncoordinated bladder and external urethral sphincter activity, termed DSD $[1-3,16,17]$. In addition, a high intravesical pressure can cause damage to the upper urinary tract, leading to vesical muscular hypertrophy $[2,18]$. Even though many studies have focused on pathophysiological alterations to the bladder neck or posterior urethra after SCI, few studies have been done regarding changes in the enlarged vesical body or hypertrophied detrusor muscle that might accompany SCI $[3,4]$.

Our results showed that the SCI group had statistically increased mRNA expression of GAPDH at 4 weeks after injury compared with the control group (Fig. 4A). GAPDH is one of the most commonly used housekeeping genes for comparing gene expression data $[19,20]$. The housekeeping genes are standards for normalizing the expression levels of a target gene. Because very few reports have evaluated the GAPDH changes in 

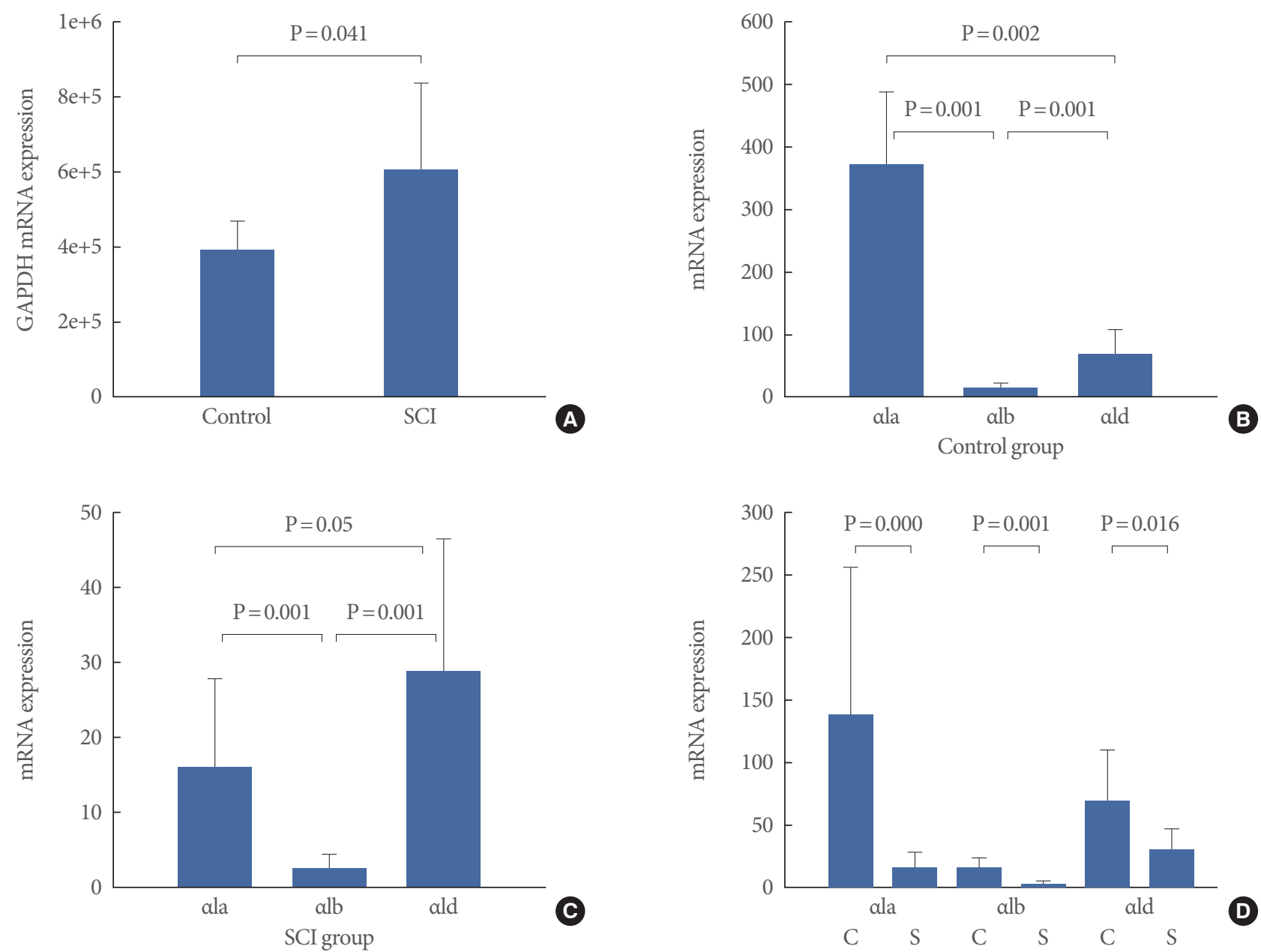

Fig. 4. The changes in mRNA expression of al adrenergic receptor (AR) subtypes and glyceraldehyde-3-phosphate dehydrogenase (GAPDH). (A) GAPDH mRNA expression in the control and the spinal cord injury (SCI) group. (B) Alphal AR subtype mRNA expression in the control group. (C) Alpha1 AR subtype mRNA expression in the SCI group. (D) Expression of each al AR subtype between the control and the SCI group. Data are reported as the mean \pm SD. C, control group; S, SCI group.

Table 2. Change in mRNA expression of $\alpha 1$ adrenergic receptor (AR) subtypes in urinary bladder after spinal cord injury

\begin{tabular}{|c|c|c|c|}
\hline & \multicolumn{3}{|c|}{ mRNA expressions (mean \pm SD) } \\
\hline & Control & Spinal cord injury & P-value \\
\hline GAPDH & $385,398 \pm 85,128$ & $607,590 \pm 229,095$ & 0.041 \\
\hline Alpha 1a $\mathrm{AR}_{\text {adj GADPH }}$ & $371.50 \pm 118.19$ & $15.90 \pm 12.13$ & 0.000 \\
\hline Alpha $1 \mathrm{~b} \mathrm{AR}_{\text {adj GADPH }}$ & $15.11 \pm 7.97$ & $2.48 \pm 2.01$ & 0.001 \\
\hline Alpha $1 d \mathrm{AR}_{\text {adj GADPH }}$ & $68.62 \pm 40.99$ & $28.94 \pm 17.61$ & 0.016 \\
\hline
\end{tabular}

GAPDH, glyceraldehyde-3-phosphate dehydrogenase.

urinary bladder after SCI, we can extrapolate the significance of the GAPDH change in the urinary bladder after SCI from the findings of the partial bladder neck obstruction model. It is well known that the DNA content and ${ }^{3} \mathrm{H}$-thymidine incorporation in the urinary bladder are increased in partially obstructed urinary bladders $[21,22]$. Our data showed that the expression of GAPDH in the SCI group was 2 times that in the controls (Table 2). For these reasons, we adjusted mRNA expression of the al AR subtypes to reflect the housekeeping effect of GAPDH.

The a $1 \mathrm{AR}$ is a member of the large family of G protein coupled receptors that mediate the actions of the endogenous catecholamines norepinephrine and epinephrine, resulting in smooth muscle contractions in body organs [4-10]. Three subtypes, $\alpha 1 \mathrm{a}$, $\alpha 1 \mathrm{~b}$, and $\alpha 1 \mathrm{~d}$, have been identified in various mammalian organs and have been characterized by either molecular or pharmacokinetic techniques [4-11]. It is well known that the three al AR subtypes expressed in the prostate play a major role in 
prostatic smooth muscle contraction [11]. The switch on the AR mediates lower urinary tract symptoms and pathophysiologic mechanisms for benign prostatic hyperplasia $[23,24]$. Quantification of al AR mRNA expression within human prostatic tissue has revealed that the ala AR predominates, followed by the ald AR and alb AR [23,24]. Furthermore, the mRNA expression of the al AR subtypes in the prostate may be a predictor of the efficacy of subtype selective AR antagonists in patients with benign prostatic hyperplasia [7,23,24].

Because lower urinary tract symptoms or pathophysiological changes in the urinary bladder resulting from bladder outlet obstruction are common disorders in urology, there are ample studies about $\alpha 1 \mathrm{AR}$ receptor subtype modulation after partial bladder outlet obstruction. For this reason, we compare the $\alpha 1$ AR mRNA modulation in the SCI model with that in the bladder outlet obstruction model induced by partial urethral ligation. Control rats show predominantly ala AR expression (68 to 74\%), followed by ald AR (21 to 28\%) and alb AR (4 to 5\%) along the whole urinary bladder [7]. However, the obstructive rat urinary bladder shows predominantly ald AR expression (77 to $74 \%$ ), followed by ala AR (21 to $24 \%$ ) and alb AR (2 to $3 \%$ ) along the whole urinary bladder [7]. Barendrecht et al. [5] evaluated the mRNA expression of the al AR subtypes by use of the real-time PCR method in rats with bladder outlet obstruction induced by partial urethral ligation. In that study, the mean relative expressions (mRNA expression fold of sham) were ald $\mathrm{AR}>$ alb AR > ala AR [5]. Interestingly, the mean relative expression of all al AR subtypes was higher in the bladder outlet obstruction group than in the sham group; however, discrepancies in subtype expression in urinary bladder were reported by Hampel et al. [7]. In control animals, $70 \%$ of $\alpha 1$ AR mRNA was the ala AR subtype, 5\% was alb AR and 25\% was ald AR, whereas in obstructed bladder, al AR expression changed to $23 \%$ ala AR, $2 \%$ alb AR, and 75\% ald AR [7]. In addition, the mRNA expression of the ala AR subtype was dramatically reduced in the partially obstructed group compared with the control rats [7]. Our results were consistent with the results from Hampel et al.'s report [7] except for one thing. The total expression of ald AR more increased than in the control animals after 6 weeks of partial outlet obstruction in Hampel et al.'s study [7]. Even though the adjusted ald AR mRNA expression was dominant among the al AR subtypes, we found that the mRNA expression of the ald AR definitively decreased less than in the control animals. Although the reasons for these differences are not yet clear, the differences may be due to different experimen- tal designs or animal models. Further studies may be needed to elucidate the meaning of the absolute decrease in all $\alpha 1 \mathrm{AR}$ subtypes in the SCI model.

Because the ald AR subtype has a 10- to 100-fold higher affinity for the endogenous neurotransmitters norepinephrine and epinephrine than does the ala or alb AR subtype, this finding provides a potentially important rationale for targeting the ald AR subtype when treating voiding symptoms after SCI [7].

To characterize the function of the $\alpha 1$ ARs in the urinary bladder, quantitative evaluation of mRNA and protein must be performed. However, it is methodologically difficult to quantitatively analyze genetic expression by use of western blotting or immunohistochemical staining. Furthermore, because the three al ARs have very similar amino acid sequences, it is very difficult to develop unique and specific antibodies for each subtype. Real-time reverse transcriptase PCR is becoming a widely used method to quantify the gene expression from cells, tissues, or tissue biopsies $[5,23,24]$.

A limitation of this study is that we did not evaluate the physiologic role of the changes in a1 AR modulation. Urodynamic studies in animals or contractile responses of harvested strips to selective a1 AR antagonists such as silodosin or naftopidil may extend our findings in the future. In addition, we evaluated al AR mRNA expression in whole bladder specimens. Because the a1 ARs are widely distributed throughout the whole urinary bladder, some expression of $\alpha 1$ ARs in the mucosa or submucosa may have affected the mRNA expression values in our experiment.

In conclusion, $\mathrm{SCI}$ modulates the $\alpha 1 \mathrm{AR}$ mRNA subtypes in rat urinary bladder. The relatively increased the ald or decreased the ala AR mRNA expression may be a therapeutic candidate for controlling symptoms of neurogenic bladder after SCI. Further studies will be needed to evaluate the action of selective $\alpha 1$ AR subtype antagonists on the urinary bladder after SCI.

\section{CONFLICT OF INTEREST}

No potential conflict of interest relevant to this article was reported.

\section{ACKNOWLEDGEMENTS}

This study was financially supported by Institute of Medical Science Research of Dankook University Medical Center in 2010. 


\section{REFERENCES}

1. Tator CH, Duncan EG, Edmonds VE, Lapczak LI, Andrews DF. Changes in epidemiology of acute spinal cord injury from 1947 to 1981. Surg Neurol 1993;40:207-15.

2. Mahfouz W, Corcos J. Management of detrusor external sphincter dyssynergia in neurogenic bladder. Eur J Phys Rehabil Med 2011;47: 639-50.

3. Abrams P, Amarenco G, Bakke A, Buczynski A, Castro-Diaz D, Harrison S, et al. Tamsulosin: efficacy and safety in patients with neurogenic lower urinary tract dysfunction due to suprasacral spinal cord injury. J Urol 2003;170(4 Pt 1):1242-51.

4. Rank MM, Murray KC, Stephens MJ, D’Amico J, Gorassini MA, Bennett DJ. Adrenergic receptors modulate motoneuron excitability, sensory synaptic transmission and muscle spasms after chronic spinal cord injury. J Neurophysiol 2011;105:410-22.

5. Barendrecht MM, Frazier EP, Vrydag W, Alewijnse AE, Peters SL, Michel MC. The effect of bladder outlet obstruction on alphal- and beta-adrenoceptor expression and function. Neurourol Urodyn 2009;28:349-55.

6. Malloy BJ, Price DT, Price RR, Bienstock AM, Dole MK, Funk BL, et al. Alpha1-adrenergic receptor subtypes in human detrusor. J Urol 1998;160(3 Pt 1):937-43.

7. Hampel C, Dolber PC, Smith MP, Savic SL, Th roff JW, Thor KB, et al. Modulation of bladder alphal-adrenergic receptor subtype expression by bladder outlet obstruction. J Urol 2002;167:1513-21.

8. Ford AP, Daniels DV, Chang DJ, Gever JR, Jasper JR, Lesnick JD, et al. Pharmacological pleiotropism of the human recombinant alpha1A-adrenoceptor: implications for alpha1-adrenoceptor classification. Br J Pharmacol 1997;121:1127-35.

9. Arai K, Tanoue A, Goda N, Takeda M, Takahashi K, Tsujimoto G. Characterization of the mouse alpha1D-adrenergic receptor gene. Jpn J Pharmacol 1999;81:271-8.

10. Yamada S, Ohkura T, Deguchi Y, Kimura R. In vivo measurement by $[3 \mathrm{H}]$ Tamsulosin of alphal adrenoceptors in rat tissues in relation to the pharmacokinetics. J Pharmacol Exp Ther 1999;289:1575-83.

11. Forray C, Noble SA. Subtype selective alpha1-adrenoceptor antagonists for the treatment of benign prostatic hyperplasia. Expert Opin Investig Drugs 1999;8:2073-94.

12. Kurizaki Y, Ishizuka O, Imamura T, Ichino M, Ogawa T, Igawa Y, et al. Relation between expression of $a(1)$-adrenoceptor mRNAs in bladder mucosa and urodynamic findings in men with lower urinary tract symptoms. Scand J Urol Nephrol 2011;45:15-9.
13. Takahashi S, Tajima A, Matsushima H, Kawamura T, Tominaga T, Kitamura T. Clinical efficacy of an alpha1A/D-adrenoceptor blocker (naftopidil) on overactive bladder symptoms in patients with benign prostatic hyperplasia. Int J Urol 2006;13:15-20.

14. Byun Y, Lee G. Changes in the expression of smooth muscle myosin heavy chain mRNA following partial bladder obstruction or spinal cord injury in rat: a preliminary study. Korean J Urol 2007;48: 522-6.

15. Kyung YS, Park HY, Lee G. Preservation of uroplakins by 2-mercaptoethanesulfonate in cyclophosphamide-induced rat cystitis. Arch Toxicol 2011;85:51-7.

16. Beckel JM, Holstege G. Neuroanatomy of the lower urinary tract. Handb Exp Pharmacol 2011;(202):99-116.

17. Valentino RJ, Wood SK, Wein AJ, Zderic SA. The bladder-brain connection: putative role of corticotropin-releasing factor. Nat Rev Urol 2011;8:19-28.

18. Wang JB, Liu CS, Tsai SL, Wei CF, Chin TW. Augmentation cystoplasty and simultaneous ureteral reimplantation reduce high-grade vesicoureteral reflux in children with neurogenic bladder. J Chin Med Assoc 2011;74:294-7.

19. Bustin SA. Absolute quantification of mRNA using real-time reverse transcription polymerase chain reaction assays. J Mol Endocrinol 2000;25:169-93.

20. Colell A, Green DR, Ricci JE. Novel roles for GAPDH in cell death and carcinogenesis. Cell Death Differ 2009;16:1573-81.

21. Saito M, Longhurst PA, Tammela TL, Wein AJ, Levin RM. Effects of partial outlet obstruction of the rat urinary bladder on micturition characteristics, DNA synthesis and the contractile response to field stimulation and pharmacological agents. J Urol 1993;150: 1045-51.

22. Malkowicz SB, Wein AJ, Elbadawi A, Van Arsdalen K, Ruggieri MR, Levin RM. Acute biochemical and functional alterations in the partially obstructed rabbit urinary bladder. J Urol 1986;136:1324-9.

23. Kojima Y, Sasaki S, Kubota Y, Imura M, Oda N, Kiniwa M, et al. Up-regulation of ala and ald-adrenoceptors in the prostate by administration of subtype selective a1-adrenoceptor antagonist tamsulosin in patients with benign prostatic hyperplasia. J Urol 2011; 186:1530-6.

24. Kojima Y, Sasaki S, Imura M, Kubota Y, Hayashi Y, Kohri K. Correlation between expression of $\alpha 1$-adrenoceptor subtype mRNA and severity of lower urinary tract symptoms or bladder outlet obstruction in benign prostatic hyperplasia patients. BJU Int 2011;107:438-42. 